\title{
Steady-State and transients measurements on a high head model francis turbine
}

\section{Short communication on model francis turbine research}

The development of renewable energy and its intermittency to the power grid network has increased the need for power regulation system. Transients operations of hydropower plants, namely startstop, load rejection, and load acceptance are widely used to regulate the power grid network. This has raised an issue of operating hydraulic turbine away from best efficiency point (BEP) which develops several unsteady phenomena such as wakes, rotor-stator interaction (RSI), pressure waves, and rotating vortex rope (RVR) in the turbine. In an extreme condition, the runner of the turbine may subject to the significant amount of vibration which causes wear and tear of the turbine components and failure of the runner and decouples it from the system.

The measurements on porotype turbines are difficult to perform due to required standstill condition and structure limitation of the hydropower plant. A scaled (1:5.1) high head model Francis turbine was selected to investigate the flow instabilities and pressure loading on the turbine components during steady-state and transients operating conditions. ${ }^{1,2}$ Both experimental and numerical investigations on model Francis turbine have been carried and the research has been published in reputed journals to promote the development and disseminate the findings. The intrusive and nonintrusive measurements techniques, such as pressure and Particle Image Velocimetry (PIV) have been selected to investigate the causes of dynamic stabilities in Francis turbine during off-design and transient operating conditions. Moreover, the measurements of basic flow parameters, such as head, discharge, torque, and runner angular speed have been performed to define its industrial significance. The guidelines available in International Electro technical Commission (IEC) were adopted to model the Francis turbine and to draw the efficiency hill diagram at all operating ranges of prototype turbine. The instrumentation, calibration, measurements, and data analysis were also performed by following the guidelines available in IEC60041 and IEC-60193.,3 The estimated uncertainty for the hydraulic efficiency was $\pm 0.15 \%$ under the steady-state operating condition of BEP.

The Francis turbine operating at part load (PL) condition has a high degree of residual swirl at the runner outlet due to mismatch of the flow angle between guide vanes outlet and runner inlet. Unsteady pressure pulsations obtained in the vaneless space and runner blades were observed high in magnitudes corresponding to the blade pass and guide vane pass frequency. The frequency of the vortex rope, i.e. $0.3 * f_{\text {runner }}$, was validated numerically from two-equation turbulence models. The result showed that the PL condition has a fully developed RVR, consisting of two components, namely rotating and plunging. The plunging (synchronous) component is developed due to water hammer in the draft tube cone length while rotating (asynchronous) component is developed across the cross section of the draft tube due to flow instabilities as vortex rope.

The operations of Francis turbine is regulated by changing the
Volume 2 Issue 3 - 2017

\author{
Bhupendra Kumar Gandhi \\ Department of Mechanical \& Industrial Engineering, ITT \\ Roorkee, India
}

Correspondence: Bhupendra Kumar Gandhi, Department of Mechanical \& Industrial Engineering, IIT Roorkee, India, Email bkgmefme@iitr.ac.in

Received: September 24, 2016 | Published: April 06, 2017

angular position of the guide vanes which respond to the load demand on the power grid network. An inappropriate movement of guide vanes during start-stop develops a significant amount of pressure loading on the turbine components. An unscheduled start-stop cycle of the turbine may also lead to the frequent refurbishment of the hydropower plant. The transient pressure measurements considering different schemes of opening and closing of guide vanes have been carried out. The pressure pulsations at the turbine inlet were directly influenced by the guide vanes movement. Turbine shutdown was observed more damaging that the turbine start-up. ${ }^{1}$ During load variations, the guide vanes experienced unsteady pressure loading and pressure differences on their surfaces which sometimes may cause the formation of the dead zone at the trailing edge of the guide vanes leading to the formation of pressure wakes. The pressure wakes from the guide vanes travels downstream in the runner and draft tube and develops vortical flow (rotating vortex rope) in the turbine. The developed vortical flow reduces the pressure recovery in the draft tube and decreases the overall efficiency of the turbine. The physical mechanism behind the formation of vortex rope is recently investigated during the load rejection operating condition of the Francis turbine. ${ }^{5}$ The formation of stagnation zone and region of high shear due to the development of high axial velocity gradients in the flow are observed to the cause the formation of vortex rope in the turbine. Investigations during emergency shutdown condition of Francis turbine was also performed and the amplitudes of pressure pulsations were observed almost double of that of the corresponding steady state condition. ${ }^{1}$ This may cause significant damages to the turbine and may create a long standstill situation for a hydropower plant.

\section{Acknowledgements}

The measurements have been carried out in collaboration between IIT Roorkee and LTU, Sweden (NTNU, Norway).

\section{Conflict of interest}

The author declares no conflict of interest.

\section{References}

1. Trivedi C. Experimental and numerical investigations on steady-state and transient characteristics of a high head model Francis turbine. Indian Institute of Technology. Roorkee, India, 2014. 
2. Goyal R, Trivedi C, Gandhi BK, et al. Transient Pressure Measurements at part load operating condition of a High ead Head Model Francis Turbine. Indian Academy of Sciences. 2016;41(11):1311-1320.

3. IEC 60041: Field acceptance tests to determine the hydraulic performance of hydraulic turbines, storage pumps, and pump-turbines. India, 1991.
4. IEC 60193: 1999-11, Hydraulic turbines, storage pumps and pumpturbines-Model acceptance tests, India.

5. Goyal R, Cervantes M, Gandhi BK. Vortex rope formation in a high head model Francis turbine. J Fluids Eng. 2016;139(4):041102-041115. 